\title{
Biogas Purification using Coconut Shell Based Granular Activated Carbon by Pressure Swing Adsorption
}

\author{
E. Akila*, S. Pugalendhi and G. Boopathi \\ Department of Bioenergy, AEC \& RI, TNAU, Coimbatore- 03, India \\ *Corresponding author:
}

\author{
A B S T R A C T
}

\section{Keywords}

Biogas purification, Activated carbon, Pressure swing adsorption, Carbon dioxide, Methane.

Article Info

Accepted:

12 March 2017

Available Online:

10 April 2017
Biogas is one of the most important renewable energy source. Biogas normally contains 55 - 65\% methane $\left(\mathrm{CH}_{4}\right)$ and $45-55 \%$ carbon dioxide $\left(\mathrm{CO}_{2}\right)$ and trace amounts of hydrogen sulphide $\left(\mathrm{H}_{2} \mathrm{~S}\right)$. Raw biogas cannot be used as vehicle fuel as it contains $\mathrm{CO}_{2}$ and $\mathrm{H}_{2} \mathrm{~S}$ which lowers the calorific value and causes corrosion to the storage vessel respectively. Enriching the biogas by removing $\mathrm{CO}_{2}$ and $\mathrm{H}_{2} \mathrm{~S}$ will significantly improve the quality of biogas. The application of biogas either as cooking fuel or engine fuel chooses the type of purification method. In this work biogas enrichment using coconut shell derived granular activated carbon as $\mathrm{CO}_{2}$ adsorbent by pressure swing adsorption (PSA) technique was investigated. The adsorption of $\mathrm{CO}_{2}$ by the adsorbent with varying pressure from 1 to 10 bar were experimentally examined. The results indicated that with increase in pressure adsorption also increases. Activated carbon (AC) showed adsorption affinity towards both $\mathrm{CO}_{2}$ and $\mathrm{CH}_{4}$ at lower pressure. As the pressure increases the material showed little higher affinity towards $\mathrm{CO}_{2}$ than $\mathrm{CH}_{4}$. The maximum methane content obtained after adsorption and $\mathrm{CO}_{2}$ reduction percent found to be $73.9 \%$ and $44.7 \%$ at 8 bar pressure respectively. The material showed lower biogas separation ability in terms of lower $\mathrm{CH}_{4}$ enrichment and lower $\mathrm{CO}_{2}$ reduction. So the selected $\mathrm{AC}$ cannot be used for biogas enrichment but it can be used for single gas adsorption.

\section{Introduction}

Biogas from anaerobic digestion of waste material is a great source for future energy needs. It is a very important source of renewable methane (Tippayawong and Thanompongchart, 2010). Biogas has low heating value $\left(6.5 \mathrm{kWh} / \mathrm{Nm}^{3}\right)$, which is approximately half that of the natural gas value (Bauer et al., 2013). Biogas can be directly used for thermal applications or if it is upgraded, it can be a used as a vehicle fuel and can replace natural gas. After methane enrichment and compression it can be used as vehicle fuel just like CNG (Vijay et al., 2006).
So enrichment of biogas is needed to convert the biogas into portable form.

A lot of processes are available for enrichment of methane content in biogas by removing significant amount of carbon dioxide $\left(\mathrm{CO}_{2}\right)$ and hydrogen sulfide $\left(\mathrm{H}_{2} \mathrm{~S}\right)$. Commonly $\mathrm{CO}_{2}$ removal processes also remove $\mathrm{H}_{2} \mathrm{~S}$.

These include absorption into liquid (physical /chemical), adsorption on solid surface, membrane separation, cryogenic separation 
and chemical conversion. Selection of the appropriate process for a particular application depends on the scale of intended operation, composition of the gas to be treated, degree of purity required and the need for $\mathrm{CO}_{2}$ recovery (MENS report, 2001).

Adsorption is one of the most economical methods of $\mathrm{CO}_{2}$ separation from biogas that has been commercialized (Grande, 2011). Among the technologies for adsorption, the pressure swing adsorption (PSA) has gained interest in the separation and capture of $\mathrm{CO}_{2}$, due to its reduced costs in energy and resources, when compared to conventional separation methods, such as absorption and distillation (Kapdi et al., 2005; Huang et al., 2006).

PSA provides high efficiency in terms of high methane enrichment. In PSA maximum of 99\% pure methane can be achieved in the pressure range of 4 to 8 bar (Urban et al., 2009). This technique works on the principle of physical adsorption.

The gas molecules will be adsorbed on the adsorbent surface under pressure and when the pressure is reduced the adsorbed gases will be released. The success of this technology lies in choosing the appropriate adsorbent material which selectively adsorb the particular gas species of concern. This posts the requirement of efficient and cost effective adsorbent that is made from locally available material. Activated carbon is one of the most widely used adsorbents because of its higher adsorptive capacity (Hung et al., 2005). AC has high surface area and porosity which makes it suitable for variety of applications.

The aim of this work was to test the coconut shell derived activated carbon which is available commercially for its ability on biogas purification and also to test the $\mathrm{CO}_{2}$ reduction capability of that material.

\section{Materials and Methods}

\section{Selection and characterization of adsorbent}

Selection of the adsorbent material is based on the properties like high surface area, total pore volume and high adsorption ability. Based on the above properties, coconut shell based granular activated carbon was selected as the adsorbent which was procured from The Jacobi Carbons India Private Limited, Coimbatore. The specification of the material was presented in table 1 . From table 1 it is clear to see that the porosity of AC is $42 \%$ and this pore volume mainly consists of mesopores and micropores. For PSA design and operation the porosity should be in the range of 0.3 to 0.5 (Jain et al., 2003). This property suggests that the material can be used for gas adsorption process. The surface morphology was studied using Quanta 250 electron microscope, FEI, Netherlands.

\section{Experimental Setup}

The adsorption experiments were performed in a lab scale PSA column with height and diameter of $1 \mathrm{~m}$ and $0.3 \mathrm{~m}$ respectively. Packing height of the column was $0.6 \mathrm{~m}$. Pall rings was provided in alternate layers in the PSA column with the adsorbent for easy distribution of gas over the cross sectional area of the column. Pall rings covers half of the total packing volume and it was provided in alternate layers with the adsorbent. The packing height of $0.6 \mathrm{~m}$ was subdivided into 6 parts each with the height of $0.1 \mathrm{~m}$. For packing the materials inside the column and to ensure partitioning of the packing materials, porous plates with $2 \mathrm{~mm}$ diameter holes were provided in between the materials at every $0.1 \mathrm{~m}$ intervals, schematic of the setup shown in figure 1 . The biogas which needs to be treated compressed to desired pressure and sent through the bottom and enriched gas was collected at the top of the column. The experiment was carried out with 
the biogas inlet pressure range of 1 to $10 \mathrm{bar}$ and at a room temperature of $30^{\circ} \mathrm{C}$. The fraction of gas components after adsorption was analyzed using GC, Nucon 5765. To evaluate the adsorption of $\mathrm{CO}_{2}$ on the adsorbent, percent of $\mathrm{CO}_{2}$ reduction was calculated as follows:

$\left(\mathrm{CO}_{2}\right.$ content of the raw biogas - $\mathrm{CO}_{2}$ content of the scrubbed biogas)

$\mathrm{CO}_{2}$ reduction, $\%=$

$\mathrm{CO}_{2}$ content of the raw biogas

\section{Results and Discussion}

\section{Surface characterization by SEM}

SEM image of selected $\mathrm{AC}$ is shown in figure 2. It can be seen from the micrographs that the external surface of the adsorbent has lot of holes and cracks with varying in size. The surface is uneven and small size pores covers maximum of its pore volume than large pores. It can be inferred from SEM image that material is suitable for gas adsorption purpose.

\section{Effect of biogas inlet pressure on $\mathrm{CO}_{2}$ reduction}

The experiment for analyzing the biogas purification ability of AC using PSA system was carried out with the pressure range of 1 to 10 bar. Table 2 shows the percentages of $\mathrm{CO}_{2}$ and $\mathrm{CH}_{4}$ gases after adsorption. The biogas initially had $47 \%$ of $\mathrm{CO}_{2}$ and $51 \%$ of $\mathrm{CH}_{4}$. From 1 to 8 bar there was a slight increase of $\mathrm{CH}_{4} \%$. So with increase in pressure, $\mathrm{CH}_{4}$ enrichment also increases. After 8 bar there was a decrease in $\mathrm{CH}_{4}$ enrichment. Initial lower methane content may due to insufficient pressure for the adsorption of $\mathrm{CO}_{2}$ into the pores of the material and if the pressure is increased adsorption of $\mathrm{CO}_{2}$ molecules into the pores of material increases.

But when the pressure further increases the adsorbed gas may be carried away with the outlet gas so the $\mathrm{CH}_{4}$ content in the outlet gas decreases. In this process, maximum methane content of $73.9 \%$ was achieved at 8 bar pressure.

Figure 3 shows the $\mathrm{CO}_{2}$ reduction percent with respect to biogas inlet pressure. As the pressure increases $\mathrm{CO}_{2}$ reduction also increases. Minimum and maximum $\mathrm{CO}_{2}$ adsorption found to be $11 \%$ and $45 \%$ at 1 bar and 8 bar respectively. Low reduction of $\mathrm{CO}_{2}$ may due to the fact that both $\mathrm{CO}_{2}$ and $\mathrm{CH}_{4}$ were absorbed by the material (Rios et al., 2013) and when the pressure increases, the material showed slight increase in adsorption of $\mathrm{CO}_{2}$ than $\mathrm{CH}_{4}$.

Table.1 Specification of AC

\begin{tabular}{|l|l|}
\hline Properties & Value \\
\hline Form & Granules \\
\hline Size & $2.5 \mathrm{~mm}$ \\
\hline Pore size & 15 to $20 \AA$ \\
\hline Bulk density & $484 \mathrm{~kg} \cdot \mathrm{m}^{-3}$ \\
\hline Porosity & 0.42 \\
\hline
\end{tabular}


Table.2 Final $\mathrm{CH}_{4}$ content after adsorption (Initial $\mathrm{CO}_{2}=47 \%, \mathrm{CH}_{4}=51 \%$ )

\begin{tabular}{|c|c|}
\hline Pressure, bar & $\mathrm{CH}_{4}$ final, $\%$ \\
\hline 1 & 57.8 \\
\hline 2 & 60 \\
\hline 3 & 63.1 \\
\hline 4 & 65 \\
\hline 5 & 66.6 \\
\hline 6 & 69.6 \\
\hline 7 & 72.8 \\
\hline 8 & 73.9 \\
\hline 9 & 72.4 \\
\hline 10 & 71.5 \\
\hline
\end{tabular}

Fig.1 Schematic illustration of PSA unit

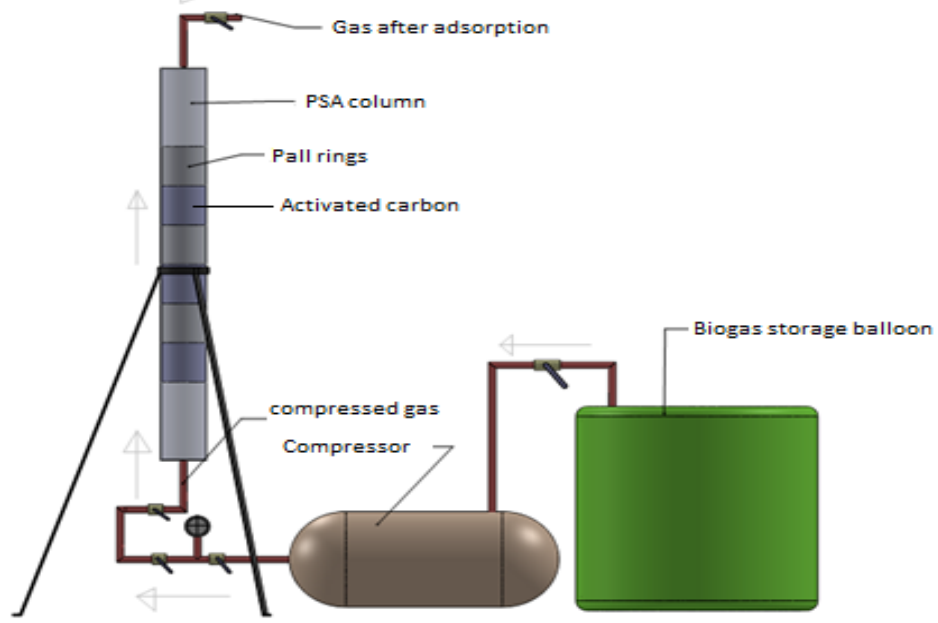

Fig.2 SEM image of AC

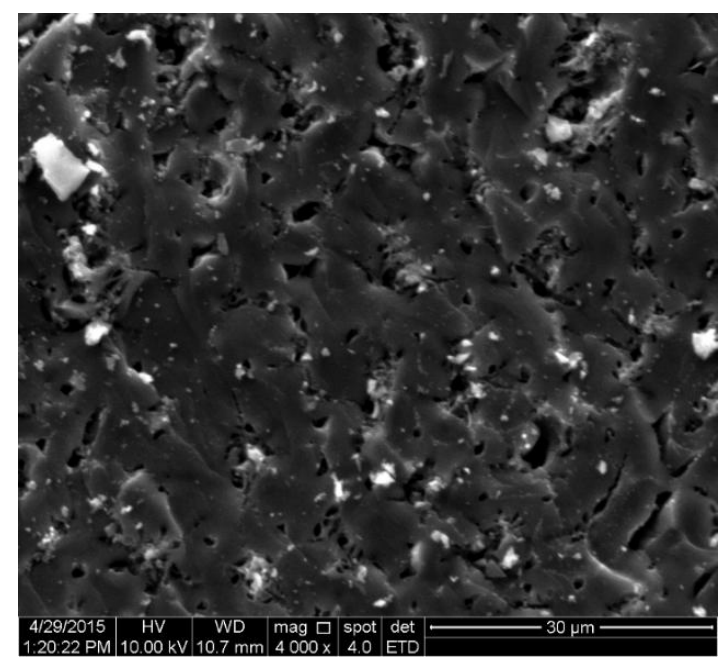


Fig.3 Effect of biogas inlet pressure on $\mathrm{CO}_{2}$ reduction

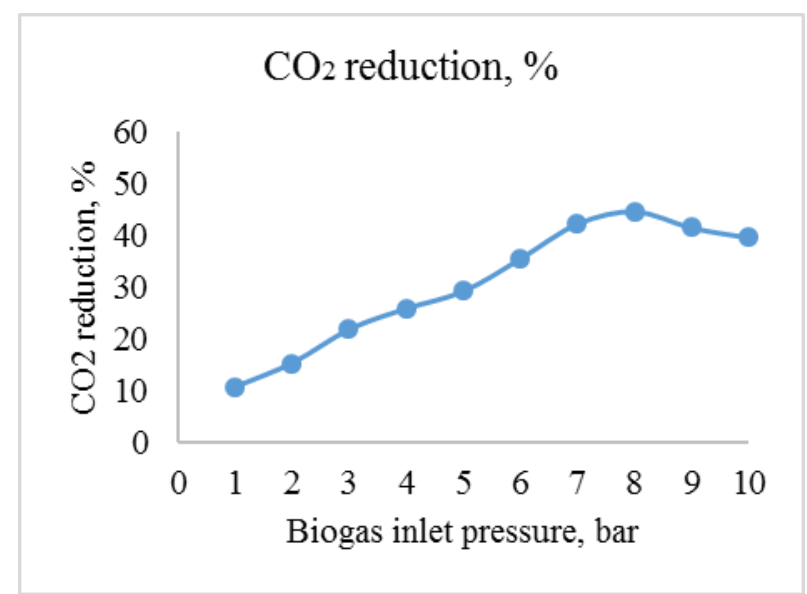

There is an initial and preferential filling of high-energy sites for which the more strongly adsorbed component $\left(\mathrm{CO}_{2}\right)$ is even more preferred in the competition for the sites than when competing for energetically weaker adsorption sites (Rios et al., 2013). The competitive nature of the two gas species was seen at higher pressure. Since $\mathrm{CO}_{2}$ is more strongly held by the adsorbent, it tends to displace the previously adsorbed $\mathrm{CH}_{4}$ (Foeth et al., 1994).

During adsorption the molecules dimension play an important role. The pore size of the material cavities is selective factor for the adsorbed molecules. As the pore size of activated carbon ( 15 to $20 \AA$ ) is greater than the molecule diameter of the gas species $\mathrm{CO}_{2}$ $\left(\begin{array}{ll}3.4 \AA & \AA\end{array}\right)$ and $\mathrm{CH}_{4} \quad\left(\begin{array}{ll}3.8 & \AA\end{array}\right)$ the selective adsorption was not accomplished and the material adsorbs both $\mathrm{CO}_{2}$ and $\mathrm{CH}_{4}$ results in less methane content in the product gas (Bonenfant et al., 2008).

In conclusion, the study was conducted to evaluate the suitability of AC for biogas purification. The material showed adsorption affinity towards both $\mathrm{CO}_{2}$ and $\mathrm{CH}_{4}$ at all pressure. Even though the material exhibited slightly higher adsorption of $\mathrm{CO}_{2}$ than $\mathrm{CH}_{4}$, the maximum $\mathrm{CO}_{2}$ reduction was only $45 \%$.
This indicates that the material has lower ability in purification of biogas. But the selected material showed better adsorption capacity of gases so it can be used for areas where single gas adsorption is required like $\mathrm{CO}_{2}$ capturing or for methane storage.

\section{References}

Bauer, F., Persson, T., Hulteberg, C. and Tamm, D. 2013. Biogas upgradingtechnology overview, comparison and perspectives for the future. Biofuels, Bioproducts and Biorefining, 7(5): 499511.

Bonenfant, D., Kharoune, M., Niquette, P., Mimeault, M. and Hausler, R. 2008. Advances in principle factors influencing carbon dioxide adsorption on zeolites. Sci. Technol. Adv. Materials, 9(1): 013007.

Foeth, F., Andersson, M., Bosch, H., Aly, G. and Reith, T. 1994. Separation of dilute $\mathrm{CO}_{2}-\mathrm{CH}_{4}$ mixtures by adsorption on activated carbon. Separation Sci. Technol., 29(1): 93-118.

Grande, C.A. 2011. Biogas upgrading by pressure swing adsorption. INTECH Open Access Publisher.

Huang, C.C., Chen, C.H. and Chu, S.M. 2006. Effect of moisture on $\mathrm{H}_{2} \mathrm{~S}$ adsorption by 
copper impregnated activated carbon. $J$. Hazardous Materials, 136(3): 866-873.

Hung, Y.T., Lo, H.H., Wang, L.K., J.R. Taricska, K.H. and Li, 2005. Granular activated carbon adsorption, in: Wang, L.K., Hung, Y.T and Shammas N.K. (Eds.), Handbook of Environmental Engineering, Humana Press, Totowa, New Jersey, 3: 573-634.

Jain, S., Moharir, A.S., Li, P. and Wozny, G. 2003. Heuristic design of pressure swing adsorption: a preliminary study. Seperation and Purification Technol., 33(1): 25-43.

Kapdi, S.S., Vijay, V.K., Rajesh, S.K. and Prasad, R., 2005. Biogas scrubbing, compression and storage: perspective and prospectus in Indian context. Renewable Energy, 30(8): 1195-1202.

Rios, R.B., Stragliotto, F.M., Peixoto, H.R., Torres, A.E.B., Bastos-Neto, M., Azevedo, D.C.S. and Cavalcante Jr, C.L. 2013. Studies on the adsorption behavior of $\mathrm{CO}_{2}-\mathrm{CH}_{4}$ mixtures using activated carbon. Brazilian J. Chem. Engi., 30(4): 939-951.

Tippayawong, N. and Thanompongchart, P. 2010. Biogas quality upgrade by simultaneous removal of $\mathrm{CO}_{2}$ and $\mathrm{H}_{2} \mathrm{~S}$ in a packed column reactor. Energy, 35(12): 4531-4535.

Urban, W., Lohmann, H. and Girod, K. 2009. Technologies and cost of biogas upgrading and feeding into the natural gas grid, Oberhausen: Fraunhofer Institute for Environmental, Safety and Energy Technol., UMSICHT.

Vijay, V.K., Chandra, R., Subbarao, P.M.V. and Kapid, S. 2006. Biogas purification and bottling into $\mathrm{CNG}$ cylinders: producing Bio- $\mathrm{CNG}$ from biomass for rural automotive applications. A paper presentation at The $2^{\text {nd }}$ Joint International Conference on Sustainable Energy and Environment (SEE), Bangkok, Thailand.

\section{How to cite this article:}

Akila, E., S. Pugalendhi and Boopathi, G. 2017. Biogas Purification using Coconut Shell Based Granular Activated Carbon by Pressure Swing Adsorption. Int.J.Curr.Microbiol.App.Sci. 6(4): 1178-1183. doi: https://doi.org/10.20546/ijcmas.2017.604.144 